\title{
Windfall Scale, Wealth Consciousness and Social Proximity as Influences on Ultimatum Game Decisions
}

\author{
Carl Vogel \\ Trinity Centre for Computing \\ and Language Studies \\ Computational Linguistics Group \\ School of Computer Science \\ and Statistics \\ Trinity College Dublin \\ The University of Dublin \\ Dublin 2, Ireland \\ Email: vogel@tcd.ie
}

Anna Esposito

\author{
Università della Campania "Luigi Vanvitelli" \\ Department of Psychology \\ and IIASS, Caserta, Italy \\ Email: iiass.annaesp@tin.it
}

\author{
Evelyn Hayes \\ Trinity Centre for Computing \\ and Language Studies \\ Computational Linguistics Group \\ School of Computer Science \\ and Statistics \\ Trinity College Dublin \\ The University of Dublin \\ Dublin 2, Ireland \\ Email: hayesev@tcd.ie
}

\author{
Deon Calawen \\ Trinity Centre for Computing \\ and Language Studies \\ Computational Linguistics Group \\ School of Computer Science \\ and Statistics \\ Trinity College Dublin \\ The University of Dublin \\ Dublin 2, Ireland \\ Email: calawend@tcd.ie
}

\begin{abstract}
The ultimatum game is a construct used to explore factors that influence decision making in economic reasoning. The game involves two players who asymmetrically encounter a windfall, but both knowing the amount of the windfall: one player proposes a division of the windfall between the two players; the other player either accepts the proposer's suggested division, and in this case the windfall is divided between the players according to the proposal, even if the responder receives nothing, or the other player rejects the proposer's offer, and in this case neither player receives anything. In this paper, influences on decisions to accept or reject offers within the ultimatum game (scale of windfall, wealth consciousness, and social proximity) are explored. Scale of windfall did not reveal an effect. Aspects of responders' socio-economic circumstances likely to associate with greater concern about finances, and therefore greater wealth consciousness, are shown to relate to a higher threshold for a minimum acceptable offer. Greater social distance between proposer and responder appears to increase rejection rates. These results demonstrate an influence of social and economic circumstances of participants on their economic reasoning.
\end{abstract}

\section{INTRODUCTION}

If one's goal is, for example, to agument human cognitive capabilities (see [1]), it is necessary to understand the properties of un-augmented cognition. Understanding how human reasoning diverges from pure rationality is important to being able to anticipate and isolate the influence of biases and attachments. The Ultimatum Game [2] has been used extensively in research that explores such factors because of a tendency within the game for participants to evidently "irrationally" reject non-zero offers that would otherwise represent free goods. Within the game there are two players, one of whom encounters a windfall and who may keep a share of that windfall only if the proposed share is agreed by the other player. Where the windfall is money, normal market reasoning would suggest that any non-zero offer that the offer-proposer makes should be acceptable to the offer-responder since it would represent pure gain. However, evidently responders are quite likely to reject any offer that they perceive as unfair, modulo some asymmetric allowance to the proposer as the one who first "touched" the windfall. To idealize: if one could identify exactly the set of factors that lead to rejection of non-zero offers one would have itemized the elements of "irrationality" that influence human economic decision making.

This paper explores the impact of wealth consciousness, scale of the overall amount of goods available (§III), and social distance between game players within the game (§IV).

\section{BACKGROUND}

\section{A. Prior research}

Many factors have been studied in connection with the ultimatum game, studying both influences on the proposer and on the responder. For example, emotional contexts (such as elicited by failure in a preceding game of chance) have been demonstrated to prime behaviors of proposers (e.g. towards lower offers) [3]. A comparable study has shown that responders, when primed by a disgust trigger, accept lower offers [4]. The focus of the present work is on the responder's decision of whether to accept an offer.

Studies have also addressed economic reasoning. It has been shown, for example, that for offers of identical percentages, the greater the overall magnitude of the windfall, ${ }^{1}$

\footnotetext{
${ }^{1}$ We refer to the magnitude of the windfall as the scale of the windfall.
} 
the less likely rejection [5]. Forcing delay in decision for several minutes has also been shown to reduce rejections [6], and forcing speeded decision has been shown to increase rejection rates [7]. Here we consider the question of the scale of the offer, but in a background context in which probable consciousness of wealth may be inferred. Among children, where consciousness of wealth is not expected to be pronounced (and in a modified task, with candy rather than money) a preference for understanding a fair offer as equal shares has been demonstrated [8].

It has been shown that social appearances influence the decisions people make in evaluating an offer in the ultimatum game, even when they are not aware of that influence [9]. The same study demonstrated sensitivity to moral descriptions of the person making the offer. Here we focus on an indirectly related factor, social proximity (under the assumption that people foster friendship (as opposed to mere acquaintanceship) with people whom they find morally compatible).

\section{B. Hypotheses}

Hypothesis 1: Wealth consciousness increases expectation for "fair" offers in the game, even where any non-zero offer would create benefit.

Hypothesis 2: Offers in relation to large amounts matter more than the percentage of the offer.

Hypothesis 3: With greater social distance there is greater inclination to reject offers.

\section{WEALTH AND OFFER SCALE}

\section{A. Methods}

An online questionnaire was developed asking a series of indirect questions about issues correlated with wealth consciousness (e.g. employment status, level of education home ownership, location of residence, etc.). The questions relate to demographic factors that impinge on a pre-theoretic notion of wealth consciousness - for example, one might imagine a person employed full-time to have fewer concerns about potential income than someone who is retired. We do not propose these quantities as a perfect inventory of wealth or wealth consciousness, but as manifestly associated factors. After these questions, participants were presented with the rules of a hypothetical new television game show.

Now imagine you are taking part in the most recent episode of "Cash Flow". You choose a box from the bag and open it. It is empty. The other participant opens a box containing $\$ 10,000$. They decide to offer you $\$ 4,000$. Remember:

1) If you accept this offer, you will receive the portion of the money in the other contestant offered you, and they get to keep the reset.

2) If you reject this offer, neither of you receive any money.

The participant is asked "Do you want to accept or reject this offer?" Each particpant plays the game exactly once. The scale of the offer is one of $\$ 100, \$ 10,000$ or $\$ 1,000,000$ (the example above is from the middle scale). The offer is either fair $(40 \%)$ or unfair $(20 \%)$ of the amount mentioned in the text.
Subsequently, participants were asked what minimum offer they would accept, whether they had heard of the ultimatum game before, what their understanding of the game was.

The experimental design received approval from the Research Ethics Committee of the School of Computer Science and Statistics of Trinity College Dublin. Participants were recruited via physical notice boards around Trinity College Dublin and online notices in the Irish communities in which the second author participates. Recruitment resulted in 153 responses. Participants were randomly allocated to the six (3 levels of scale $\mathrm{x} 2$ levels of offer fairness) condition types. Of these 153 responses, 147 were retained for analysis, responses eliminated either because participants opted out of answering the question of whether to accept or reject the offer or because the open text field revealed that the participant engaged in the experiment in the spirit of vandalism [10], [11]. A summary of the age ranges of participants is indicated in Table I.

TABLE I. AGE RANGES AND THEIR COUNTS OF PARTICIPANTS

\begin{tabular}{l|ccccc} 
Age Range & $18-24$ & $25-34$ & $35-44$ & $45-54$ & $55-64$ \\
\hline Count & 92 & 19 & 11 & 7 & 18
\end{tabular}

\section{B. Results}

Of the 147 responses, only eight were decisions to reject the offer. Table II indicates how these distributed across the age-ranges attested among participants. Table III illustrates

TABLE II. DECISION TYPE ACROSS AGE RANGES

\begin{tabular}{l|ccccc} 
& \multicolumn{5}{|c}{ Age } \\
Decision & $18-24$ & $25-34$ & $35-44$ & $45-54$ & $55-64$ \\
\hline Accept & 89 & 18 & 9 & 7 & 16 \\
Reject & 3 & 1 & 2 & 0 & 2
\end{tabular}

TABLE III. DECISION TYPE IN RELATION TO OFFER TYPE

\begin{tabular}{l|cc} 
& \multicolumn{2}{|c}{ Offer Type } \\
Decision & Fair & Unfair \\
\hline Accept & 73 & 66 \\
Reject & 4 & 4
\end{tabular}

that the decisions to reject were evenly split between fair and unfair offers. The influence of scale of the offer is indicated in Table IV. The rejections concentrate at the least end of the scale, while acceptances distribute evenly across levels of scale. As more than $20 \%$ of the contingency table yield expected counts less than 5 , a chi-square test of significance is not warranted [12], nor is the resulting chi-square statistic significant if computed without regard to convention.

TABLE IV. DECISION TYPE IN RELATION TO OFFER TYPE

\begin{tabular}{l|ccc} 
& \multicolumn{3}{|c}{ Scale } \\
Decision & 100 & 10000 & 1000000 \\
\hline Accept & 45 & 46 & 48 \\
Reject & 5 & 1 & 2
\end{tabular}

The large number of offer acceptances makes it all the more interesting to explore the threshold for offer acceptances indicated by participants after their initial decision. Table $\mathrm{V}$ indicates the counts of individuals for each of the possible levels of acceptance thresholds provided. The level 0 corresponds to a response that the participant would accept any offer.

Table VI shows how the threshold of being offered at least $50 \%$ distributed across actual decision types, given offer types. 
TABLE V. PERCENTAGE OFFER EXPRESSED AS NECESSARY FOR ACCEPTANCE

\begin{tabular}{l|cccccccc} 
& \multicolumn{8}{|c}{ Acceptance threshold percentage } \\
Decision & 0 & 10 & 20 & 30 & 40 & 50 & 100 & NA \\
\hline Accept & 103 & 18 & 8 & 4 & 2 & 2 & 0 & 2 \\
Reject & 0 & 0 & 0 & 1 & 0 & 5 & 1 & 1
\end{tabular}

TABLE VI. COUNTS OF INDIVIDUALS WHO WOULD ACCEPT OFFERS OF AT LEAST 50\%, BY OFFER TYPE AND DECISION TYPE

\begin{tabular}{|c|c|c|c|c|}
\hline \multirow[b]{3}{*}{ Decision } & \multicolumn{2}{|c|}{ Acceptance Threshold $<50 \%$} & \multicolumn{2}{|c|}{ Acceptance Threshold $\geq 50 \%$} \\
\hline & & Type & & Type \\
\hline & Fair & Unfair & Fair & Unfair \\
\hline Accept & 70 & 65 & 1 & 1 \\
\hline Reject & 0 & 1 & 4 & 2 \\
\hline
\end{tabular}

The individual who rejected the unfair offer of $20 \%$ would have accepted $30 \%$. The fact that one person who rejected the amount offered would have accepted an offer of $100 \%$ indicates that perceived equality was not univocally the main motivating factor behind the decision. ${ }^{2}$ The individuals who rejected the offer were more likely to express an interest in an offer of at least $50 \%$ than those who accepted the offer (fair or unfair) $\left(\chi^{2}=74.76, d f=1, p<2.2 * 10^{-16}\right)$.

We also analyze the acceptance threshold percentage directly as a response variable. However, it is implicit in Table $\mathrm{V}$ that this quantity is not normally distributed, given that the majority indicated that they would have accepted any offer. Therefore, non-parametric tests are used to test significance of effects. Table VII shows that the mean of the acceptance threshold does not have a clear (monotonic) relationship to the scale of the amount involved in the offer.

TABLE VII. MEAN OF PERCENTAGE ACCEPTANCE THRESHOLD IN RELATION TO SCALE OF AMOUNT TO BE SHARED

\begin{tabular}{r|c} 
Scale & Acceptance threshold \\
\hline 100 & 9.592 \\
10000 & 5.000 \\
1000000 & 6.531
\end{tabular}

TABLE VIII. MEAN OF PERCENTAGE ACCEPTANCE THRESHOLD IN RELATION TO EMPLOYMENT STATUS

\begin{tabular}{l|l|r}
$n$ & Employment Status & Acceptance Threshold \\
\hline 77 & Employed & 8.421 \\
1 & Homemaker & NA \\
1 & Military & 0.000 \\
4 & Unemployed & 12.500 \\
5 & Retired & 20.000 \\
3 & Self-employed & 10.000 \\
55 & Student & 3.704 \\
1 & NA & -
\end{tabular}

Employment status (see Table VIII) appears to have a significant effect (Kruskal-Wallis $\chi^{2}=12.162, d f=5, p=$ 0.03263): the greatest mean acceptance threshold is among retired participants, followed by those not employed and selfemployed. Table IX shows that the mean of participants' indication of their acceptance threshold does not correspond linearly with the number of annual holidays they take. In Table $\mathrm{X}$ a higher mean acceptance threshold for full-time than for part-time participants is shown; however, the difference is not significant $(W=1787.5, p=0.2003$ ). Table XI shows that the acceptance threshold does not linearly relate to the number of individuals reported as contributing to the

\footnotetext{
${ }^{2}$ In this case, the response indicates accepting only offers in which the proposer receives nothing, and it is difficult to defend this as fair.
}

participant's household income. In relation to the question of whether the participant contributes to the household income as main provider or joint provider Table XII shows that there is an effect of increase in mean acceptance threshold with the increase of the participant's percentage contribution to household income, analyzed in categorical terms (KruskalWallis $\chi^{2}=8.7853, d f=2, p=0.01237$ ).

TABLE IX. MEAN OF PERCENTAGE ACCEPTANCE THRESHOLD IN RELATION TO NUMBER HOLIDAYS PARTICIPANTS TAKE ANNUALLY

\begin{tabular}{l|ccccc} 
Holidays & 0 & 1 & 2 & 3 & $3+$ \\
\hline Mean Acceptance Threshold & 2.353 & 6.909 & 5.652 & 13.636 & 10.714
\end{tabular}

TABLE X. MEAN OF PERCENTAGE ACCEPTANCE THRESHOLD IN RELATION TO EMPLOYMENT MODEL

\begin{tabular}{c|c} 
EmploymentModel & AcceptThreshold \\
\hline Full time & 8.414634 \\
Part time & 6.153846
\end{tabular}

TABLE XI. MEAN OF PERCENTAGE ACCEPTANCE THRESHOLD IN RELATION TO NUMBER HOLIDAYS PARTICIPANTS TAKE ANNUALLY

\begin{tabular}{l|cccccc} 
Household incomes & 0 & 1 & 2 & 3 & 4 & 5 \\
\hline Mean acceptance threshold & 5.000 & 10.000 & 7.045 & 5.200 & 11.818 & 3.333
\end{tabular}

TABLE XII. MEAN OF PERCENTAGE ACCEPTANCE THRESHOLD IN RELATION TO PARTICIPANT PARTICIPATION IN HOUSEHOLD INCOME

\begin{tabular}{c|c} 
Participation in household income & Mean acceptance threshold \\
\hline No & 4.731 \\
Joint & 11.200 \\
Main provider & 12.608
\end{tabular}

While there is not a linear relationship between the number of years of employment and mean acceptance threshold, there is a trend: see Table XIII; considered as categories, the differences across categories that suggests a higher threshold of acceptance with a greater number of years' employment (Kruskal-Wallis $\chi^{2}=16.299, d f=8, p=0.03829$ ). Marital status also yields a significant effect (Kruskal-Wallis $\chi^{2}=$ 8.3595, $d f=2, p=0.0153)$ : the counts are shown in Table XIV.

\section{Discussion}

It has been shown that years of employment, marital status, and percentage contribution to household income all have a significant interaction with the threshold percentage offer that participants reported as necessary for their acceptance. These quantities are related to wealth, but do not determine wealth. The fact that the number of individuals contributing to household income did not show significance undermines the claim that household wealth is the main overarching factor here. One might consider the effect of age further in this light, given that years of employment is constrained by age. Again, treating the age ranges as categorical variables there, is a significant effect here (Kruskal-Wallis $\chi^{2}=21.114, d f=$ $4, p=0.0003005)$; however, the effect is not linear with age, as shown in Table XV. One might reach a conclusion that probable sensitivity to wealth has a greater influence than wealth correlates. The discussion of employment status categories supports this: students and employed individuals showed the least mean threshold in the percentage of an acceptable offer, while retired and unemployed participants indicated the greatest threshold. Circumstances of the responder that appear 
TABLE XIII. MEAN OF PERCENTAGE ACCEPTANCE THRESHOLD IN RELATION TO DURATION OF EMPLOYMENT

\begin{tabular}{c|c|c}
$n$ & Years of Employment & AcceptThreshold \\
\hline 40 & $<1$ & 6.500000 \\
30 & $1-2$ & 4.666667 \\
5 & $2-3$ & 0.000000 \\
9 & $3-4$ & 3.750000 \\
1 & $4-5$ & 0.000000 \\
1 & $5-6$ & 0.000000 \\
2 & $6-7$ & 10.000000 \\
2 & $7-8$ & 0.000000 \\
0 & $8-9$ & 0.000000 \\
29 & $10+$ & 16.206897 \\
28 & NA & -
\end{tabular}

TABLE XIV. MEAN OF PERCENTAGE ACCEPTANCE THRESHOLD IN RELATION TO DURATION OF MARITAL STATUS

\begin{tabular}{c|c|c}
$n$ & Marital Status & AcceptThreshold \\
\hline 35 & Married & 13.333 \\
2 & Separated & 10.000 \\
106 & Single & 5.333 \\
4 & NA & -
\end{tabular}

TABLE XV. MEAN OF PERCENTAGE ACCEPTANCE THRESHOLD IN RELATION TO AGE

\begin{tabular}{l|c|c}
$n$ & Age & AcceptThreshold \\
\hline 92 & $18-24$ & 5.055 \\
19 & $25-34$ & 4.737 \\
11 & $35-44$ & 22.000 \\
7 & $45-54$ & 0.000 \\
18 & $55-64$ & 14.706
\end{tabular}

at face value to associate with consciousness of wealth further associate with a higher threshold for the minimum percentage of an offer deemed fair.

While the research design created two response variables: the decision to accept or reject and the acceptance threshold, it is noteworthy that such a small proportion of participants rejected the offer. At least two possible explanations suggest themselves. One is in the nature of the scenario presented in which participants are asked to imagine that the offer was provided after their own possibility of being the proposer in the game proved null: their own box containing a potential windfall was empty. They are then responding to their partner's offer. This feature of the construction may nudge participants towards imagining that their partner has a greater entitlement to the amount in their box. The construction very nearly amounts to having played the game twice, once in each role; however, it is not a foregone conclusion that repeated games with the same partner lead to greater levels of acceptances [13]. The second possibility is in the anonymous nature of the partner in the game: no information is given to participants about who their partner might be. Given this, it is not possible to determine whether they constructed a mental image of their partner at all or whether they did so as someone unfamiliar or familiar, and if familiar, whether the person was imagined as someone with proximal or distal social distance. The next section addresses the question of social proximity.

\section{Social DistancE}

\section{A. Methods}

An online questionnaire was developed. The game was presented in concise terms, without the game show construction. Prospective participants were informed as follows:
The ultimatum game is simple. The game is played by two players who are shown a sum of money, say 10. One player (the Proposer) is asked to split the money between himself/herself and the other player. The other player (the Responder) can either accept or refuse the offer. If the other player accepts the offer, the money is shared according to the offer. However, if the other player refuses the offer then both players get nothing.

This study did not manipulate the scale of the offer, nor were questions about wealth presented. ${ }^{3}$ The manipulated variable was social proximity, with participants asked to imagine participating in the game with a stranger, an acquaintance or a close friend. Participants were randomly allocated to one of these social proximity conditions. To prime focus on social proximity, participants were presented with a narrative that explicitly asked them to imagine the person, as in the following. The narrative mentioned either the stranger, acquaintance or close friend, as appropriate to the condition assigned.

Picture an acquaintance of yours, this would be a person who you have met but dont know very well. Imagine that your acquaintance is wearing a red hat and white runners. The hat and runners were given to your acquaintance as a gift.

The same acquaintance has been given $€ 10$. Your acquaintance is then asked to share this money with you. Out of the $€ 10$, your acquaintance can offer to give you any amount. But there is a condition. If you decide accept your acquaintances offer, you both get to split the money according to the offer. However, if you decide to reject the offer, you and your acquaintance will both receive nothing.

The offer type was either fair $(€ 4)$ or unfair $(€ 1)$. While social distance was constructed with three levels, we also intended a binary version of the variable ("acquaintance" and "friend" understood as "familiar" and "stranger", as "unfamiliar").

The experimental design received approval from the Research Ethics Committee of the School of Computer Science and Statistics of Trinity College Dublin. Participants were recruited via physical notice boards and flyers around Trinity College Dublin, with contact details of the third author. To support "snow-ball" recruitment, participants were encouraged to forward the questionnaire to others known to them. Recruitment resulted in 96 participants, each randomly allocated to an experimental condition (3 levels of social distance $\mathrm{x} 2$ offer types). Table XVI shows that there was a greater propensity to reject an unfair offer than in the other experiment.

\section{TABLE XVI. DECISION TYPE IN RELATION TO OFFER TYPE}

\begin{tabular}{l|cc} 
& \multicolumn{2}{|c}{ Offer Type } \\
Decision & Fair & Unfair \\
\hline Accept & 38 & 30 \\
Reject & 10 & 18
\end{tabular}

\footnotetext{
${ }^{3}$ Recall that the first study exhibited low rejection rates and that previous research has shown higher rejection rates in response to smaller magnitudes, even where varying magnitudes do not correspond to varying windfall percentages offered [5].
} 


\section{B. Results}

The distribution of responses by offer type and the twolevel measure of social distance is shown in Table XVII and in relation to the three-level measure in Table XVIII.

TABLE XVII. DECISION TYPE IN RELATION TO OFFER TYPE AND BINARY SOCIAL DISTANCE

\begin{tabular}{l|l|cc} 
& & \multicolumn{2}{|c}{ Offer Type } \\
Fair & Unfair \\
Social Proximity & Response & & \\
\hline Familiar & Accept & 28 & 23 \\
Unfamiliar & Reject & 4 & 9 \\
& Accept & 10 & 7 \\
& Reject & 6 & 9
\end{tabular}

TABLE XVIII. DECISION TYPE IN RELATION TO OFFER TYPE AND THREE-LEVELS OF SOCIAL DISTANCE

\begin{tabular}{l|l|cc} 
& & \multicolumn{2}{|c}{ Offer Type } \\
Fair & Unfair \\
Social Proximity & Response & & \\
\hline Friend & Accept & 15 & 13 \\
& Reject & 1 & 3 \\
Acquaintance & Accept & 13 & 10 \\
Stranger & Reject & 3 & 6 \\
& Accept & 10 & 7 \\
& Reject & 6 & 9
\end{tabular}

A log-linear model testing association between the binary version of social proximity and response type is significant ( $p=0.0069505)$, with participants more likely to accept offers and less likely to reject offers from familiar proposers and less likely to accept offers and more likely to reject offers from unfamiliar proposers, than if there were no interaction. This two-variable interaction is also significant for the three-level coding of social distance ( $p=0.010171)$ (there is a difference in magnitude of residuals between friends and acquaintances, but they remain in the same direction in distinction to the residuals associated with strangers). Using a log-linear model to test the association among offer type, response type and the binary model of social proximity, the null hypothesis that there is no interaction among the variables may be rejected $(p<$ 0.032 ). The magnitude of residuals is such that the number of rejections of unfair offers made by unfamiliar individuals is larger than would be expected without interaction $(p<0.05)$. Using the three-level model of social proximity, the overall interactions do not achieve significance $(p=0.08515)$, and the magnitude of the rejections of offers by strangers only approaches significance as well.

\section{Discussion}

It is noteworthy that this experiment had fewer recalcitrant responses than the experiment described in $\S$ III. Presumably, the inventory of questions prior to the actual game in the $\S$ III experiment was more off-putting. As expected, social distance has an impact, with greater social distance creating a greater inclination to reject an offer, unfair offers rejected more than fair offers, in any case.

\section{REFLECTIONS}

There were more rejections of offers (fair and unfair) in the experiment of $\S I V$ than of $\S$ III. The rejections are sensitive to offer type (fair vs. unfair) in the $\S I V$ experiment but not the $\S$ III one. While the pattern of rejection in $\S I V$ increases with greater social distance, the level of social distance that demonstrates least sensitivity to offer type is the case of the stranger. In abstract terms, that is an approximate description of the results in the $\S$ III experiment. However, the condition with the greatest difference between overall acceptances and rejections, with more acceptances is the case of the friend, and in those abstract terms, this too is an approximate description of the results of the first experiment. The results in $\S I V$ while interesting in their own right, do not disambiguate whether the participants described in $\S$ III imagined participating in the game show with a friend, an acquaintance or a stranger.

We return to the hypotheses articulated at the outset (§II-B). We have found that personal circumstances of responders that one may reasonably imagine to increase wealth consciousness appear to associate with increased thresholds for what counts as a fair offer, thus supporting the first hypothesis. We did not find support for the second hypothesis that offers in relation to large amounts matter more than the percentage of the offer, given that the overall rejection rate was so low in the first experiment. The second experiment adopted a very small windfall scale, by comparison with the first experiment, and the number of rejections was much greater among a smaller number of participants (28 offer rejections of 96 participants in the second experiment vs. 8 of 147 in the first experiment); however, we decline to pool the data between the two to analyze this more deeply, given the other differences between the two experiments. The second experiment produced support for the third hypothesis: with greater social distance there is greater inclination to reject offers.

These results establish that there is a need to analyze more deeply the concept of wealth consciousness addressed here. We have presumed that wealth consciousness need not be identical with immediate concern about personal finances, although such a concern may well give rise to wealth consciousness. One may imagine that someone who has immediate concerns about personal finances (such as, perhaps, a student) might have a different level of wealth consciousness than someone who has immediate concerns about personal finances and also worry that the immediate situation may be long term and indefnite (such as, perhaps, someone who has been without employment for a long period). One may imagine that a sole contributor to a household income is has a different sort of consciousness of wealth to someone in a household whose income has more than one source. These are suggestive suppositions, but the construct of wealth consciousness requires more extended analysis and empirical exploration.

\section{CONCLUSIONS}

This work is relevant to the field of cognitive infocommunications [1], [14], [15], [16], [17]. We take this field, like most technical domains, to have a scientific side and an engineering side. That is, one may presume that it is a goal of "coginfocom", from an engineering perspective, to extend the capabilities of humans by providing technologies that enhance their capacity to interact successfully within the world. ${ }^{4}$ On this view, telephones and lever-fulcrum combinations are both innovations that extend the capacities of humans to interact

\footnotetext{
${ }^{4}$ Taking "interact" very broadly, to include both communicating with other humans and functioning in physical environments.
} 
with the world. Independently, one may may presume that it is a goal of coginfocom, from a scientific perspective, to understand the dynamics of human cognition and communication. This work contributes in the latter manner, but this work is not alone in the field in trying to contribute to knowledge about the base-line provided by un-augmented humans (such work explores many dimensions of human perception, thought and interaction; see, for example, [18], [19], [20], [21], [22], [23]). Moreover, these two sides of coginfocom are not in opposition. ${ }^{5}$ For example, it may well be a consequence of success in this research into understanding how people respond to the ultimatum game as it is embedded in human-human interactions that it becomes possible to build better artificial personal agents, more sensitive to the biases that humans use in analyzing the world, and able to filter information presented to humans in avoidance of distortions that might confuse their decision making. The completeness and incompleteness theorems are triumph of twentieth century research in mathematical logic, with profound ramifications for automated reasoning; the classification of foibles of human reasoning with negation are a comparable triumph of cognitive science, with equally profound ramifications within human reasoning. The study of automated reasoning complements the study of human reasoning. Never the twain shall part. ${ }^{6}$

\section{ACKNOWLEDGMENT}

This research is supported by Science Foundation Ireland (SFI) through the CNGL Programme (Grant 12/CE/I2267 and 13/RC/2106) in the ADAPT Centre (www.adaptcentre.ie)

\section{REFERENCES}

[1] P. Baranyi and A. Csapo, "Definition and synergies of cognitive infocommunications," Acta Polytechnica Hungarica, vol. 9, no. 1, pp. 67-83, 2012.

[2] W. Güth, R. Schmittberger, and B. Schwarze, "An experimental analysis of ultimatum bargaining," Journal of Economic Behavior \& Organization, vol. 3, no. 4, pp. 367-388, 1982

[3] O. Matarazzo, B. Pizzini, C. Greco, and M. Carpentieri, "Effects of a chance task outcome on the offers in the ultimatum game: The mediation role of emotions," in 7th IEEE International Conference on Cognitive Infocommunications (CogInfoCom 2016), P. Baranyi et al., Eds. IEEE, 2016, pp. 295-300

[4] N. Boninia, C. Hadjichristidis, K. Mazzocco, M. L. Dematté, A. Sbarbati, and S. Magon, "Pecunia olet: The role of incidental disgust in the ultimatum game," Emotion, vol. 11, no. 4, pp. 965-969, 2011.

[5] S. Anderson, S. Ertaç, U. Gneezy, M. Hoffman, and J. A. List, "Stakes matter in ultimatum games," American Economic Review, vol. 101, no. 7, pp. 3427-3439, 2011.

[6] V. Grimm and F. Mengel, "Let me sleep on it: Delay reduces rejection rates in ultimatum games," Economic Letters, vol. 111, no. 2, pp. 113115, 2011.

[7] M. Sutter, M. Kocher, and S. Strauß, "Bargaining under time pressure in an experimental ultimatum game," Economic Letters, vol. 81, no. 3, pp. 341-347, 2003.

[8] M. Wittig, K. Jensen, and M. Tomasello, "Five-year-olds understand fair as equal in a mini-ultimatum game," Journal of Experimental Child Psychology, vol. 116, no. 2, pp. 324-337, 2013.

\footnotetext{
${ }^{5}$ Furthermore, we too are involved in studying situations with augmentations for human cognition and interaction (see, for example, [24], [25]).

${ }^{6}$ With apologies to Rudyard Kipling: "Oh, East is East, and West is West, and never the twain shall meet..." The Ballad of East and West 1889.
}

[9] A. Esposito, A. M. Esposito, M. Esposito, F. Scibelli, G. Cordasco, C. Vogel, and N. Bourbakis, "How traders' appearances and moral descriptions influence recievers' choices in the ultimatum game," in 2017 International Conference on Tools with Artificial Intelligence, 2017, pp. 409-416.

[10] C. Hewson, C. Vogel, and D. Laurent, Internet Research Methods, 2nd Ed. London: SAGE, 2016.

[11] C. Hewson, D. Laurent, and C. Vogel, "Proper methodologies for psychological and sociological experiments administered via internet," Behavior Research Methods, Instruments, \& Computers, vol. 28, no. 2, pp. 186-191, 1996.

[12] H. T. Reynolds, "Analysis of nominal data," in Basic Statistics, Volume 1, M. S. Lewis-Beck, Ed. SAGE: London, 1993, pp. 159-234.

[13] T. Slembeck, "Reputations and fairness in bargaining - experimental evidence from a repeated ultimatum game with fixed opponents," EconWPA, Experimental, 1999. [Online]. Available: https://EconPapers. repec.org/RePEc:wpa:wuwpex:9905002

[14] G. Sallai, "The cradle of cognitive infocommunications," Acta Polytechnica Hungarica, vol. 9, no. 1, pp. 171-181, 2012.

[15] P. Baranyi, A. Csapo, and P. Varlaki, "An overview of research trends in CogInfoCom," in IEEE 18th International Conference on Intelligent Engineering Systems, ser. INES. IEEE, 2014, pp. 181-186.

[16] P. Baranyi, A. Csapo, and G. Sallai, Cognitive Infocommunications (CogInfoCom). Springer, 2015.

[17] A. Esposito, A. M. Esposito, and C. Vogel, "Needs and challenges in human computer interaction for processing social emotional information," Pattern Recognition Letters, vol. 66, pp. 41-51, 2015.

[18] C. Vogel and L. Mamani Sanchez, "Epistemic signals and emoticons affect kudos," in 3rd IEEE Conference on Cognitive Infocommunications, P. Baranyi, Ed., 2012, pp. 517-522.

[19] B. Lewandowska-Tomaszczyk and P. A. Wilson, "Compassion, empathy and sympathy expression features in affective robotics," in 2016 7th IEEE International Conference on Cognitive Infocommunications (CogInfoCom), 2016, pp. 65-70.

[20] J. Reverdy and C. Vogel, "Linguistic repetitions, task-based experience and a proxy measure of mutual understanding," in 8th IEEE International Conference on Cognitive Infocommunications (CogInfoCom 2017), P. Baranyi, A. Esposito, P. Földesi, and T. Mihálydeák, Eds. IEEE, 2017, pp. 395-400.

[21] A. Esposito, A. M. Esposito, I. Cirillo, L. Panfilo, F. Scibelli, M. Maldonato, and C. Vogel, "Differences between hearing and deaf subjects in decoding foreign emotional faces," in 8th IEEE International Conference on Cognitive Infocommunications (CogInfoCom 2017), P. Baranyi, A. Esposito, P. Földesi, and T. Mihálydeák, Eds. IEEE, 2017, pp. 175180.

[22] C. Vogel, M. Ribeiro Lopes, and A. Esposito, "Gender differences in the language of the map task dialogues," in 8th IEEE International Conference on Cognitive Infocommunications (CogInfoCom 2017), P. Baranyi, A. Esposito, P. Földesi, and T. Mihálydeák, Eds. IEEE, 2017, pp. 151156.

[23] Á. Török, Z. G. Török, and B. Tölgyesi, "Cluttered centres: interaction between eccentricity and clutter in attracting visual attention of readers of a 16th century map," in 8th IEEE International Conference on Cognitive Infocommunications (CogInfoCom 2017), P. Baranyi, A. Esposito, P. Földesi, and T. Mihálydeák, Eds. IEEE, 2017, pp. 433-437.

[24] H. Akira, C. Vogel, N. Campbell, and S. Luz, "Perception changes with and without a video channel: A study from a speech-to-speech, machine translation mediated map task," in 8th IEEE International Conference on Cognitive Infocommunications (CogInfoCom 2017), P. Baranyi, A. Esposito, P. Földesi, and T. Mihálydeák, Eds. IEEE, 2017, pp. 401-406.

[25] J. Reverdy, H. Akira, and C. Vogel, "Alignment in a multimodal interlingual computer-mediated map task corpus," in Proceedings of the Eleventh International Conference on Language Resources and Evaluation (LREC 2018), H. Koiso and P. Paggio, Eds. Paris, France: European Language Resources Association (ELRA), 2018, pp. 55-59, Workshop on Language and body in real life \& Multimodal Corpora 2018. 